\title{
A CONSTRUÇÃO COLETIVA DO INVENTÁRIO DA REALIDADE NA EDUCAÇÃO DO CAMPO
}

\author{
LÍNLYA SACHS ${ }^{1}$ \\ Whendelly Lorena Leite Alves ${ }^{2,3}$
}

\begin{abstract}
RESUMO: Esta pesquisa se insere no âmbito da Educação do Campo, ao se debruçar sobre um instrumento idealizado para ser utilizado nas escolas em áreas de reforma agrária, como parte de uma proposta pedagógica: o inventário da realidade, documento no qual se apresenta um registro organizado de aspectos materiais ou imateriais da comunidade. O objetivo é apresentar o processo de construção coletiva do inventário da realidade por profissionais de duas escolas do campo, problematizar essa construção e discutir os resultados obtidos. Conclui-se que o inventário da realidade possui potencialidades para ser construído e utilizado por escolas em áreas de reforma agrária (mas não apenas), com o interesse de superar o desconhecimento da realidade local.
\end{abstract}

Palavras-chave: Educação do Campo. Escolas do campo. Inventário da realidade. Pesquisa-ação.

\section{THE COLLECTIVE CONSTRUCTION OF THE REALITY INVENTORY IN RURAL EDUCATION}

\begin{abstract}
The scope of this research is on Rural Education, by looking at an instrument idealized to be used in the schools located in agrarian reform areas, as part of a pedagogical proposal: the reality inventory, a document which presents an organized register of material or immaterial aspects of the community. Professionals from two rural schools collectively constructed the reality inventory for their area and the objective of this paper is to present their process, discuss their construction, and the results obtained. It is concluded that the reality inventory has the potential to be constructed and used by schools in areas of agrarian reform (but not only), with an interest in overcoming the ignorance of their local circumstances.
\end{abstract}

Keywords: Rural Education. Rural schools. Reality inventory. Action research.

Esta pesquisa advém do desenvolvimento da dissertação de mestrado intitulada "Da realidade ao inventário: a construção coletiva do inventário da realidade na Educação do Campo", realizada no Programa de Pós-graduação em Ensino de Matemática da Universidade Tecnológica Federal do Paraná.

1.Universidade Tecnológica Federal do Paraná - Cornélio Procópio (PR), Brasil. E-mail: linlyasachs@yahoo.com.br

2.Secretaria Municipal de Educação da Prefeitura de Londrina - Londrina (PR), Brasil. E-mail: whendelly_lorena@hotmail.com 3.Universidade Tecnológica Federal do Paraná - Cornélio Procópio (PR), Brasil.

Editor de Seção: Carmen Sylvia Vidigal Moraes 


\title{
LA CONSTRUCCIÓN COLECTIVA DEL INVENTARIO DE LA REALIDAD EN LA EDUCACIÓN RURAL
}

\begin{abstract}
RESUMEN: Esta investigación se enmarca en el campo de la Educación Rural, al buscar un instrumento idealizado para ser utilizado en las escuelas de áreas de reforma agraria, como parte de una propuesta pedagógica: el inventario de la realidad, un documento en el que se presenta un registro organizado de aspectos materiales o inmateriales de la comunidad. El objetivo es presentar el proceso de construcción colectiva del inventario de la realidad por profesionales de dos escuelas rurales, discutir esta construcción y los resultados obtenidos. Se concluye que el inventario de la realidad tiene potencial para ser construido y utilizado por escuelas en áreas de reforma agraria (pero no solo), con interés en superar el desconocimiento de la realidad local.
\end{abstract}

Palabras clave: Educación Rural. Escuelas rurales. Inventario de la realidad. Investigación-acción.

\section{Introdução}

$\mathrm{E}$

sta pesquisa insere-se no âmbito da Educação do Campo, ao se debruçar sobre um instrumento idealizado para ser utilizado nas escolas do campo em áreas de reforma agrária, como parte de uma proposta pedagógica: o inventário da realidade. De acordo com Hammel, Farias e Sapelli, ele "consiste em [um] diagnóstico etnográfico preciso e detalhado da realidade na qual estão situadas as escolas e sua construção" $(2015$, p. 74).

A construção coletiva do inventário da realidade faz parte das diretrizes pedagógicas para escolas do campo em áreas de reforma agrária, propostas pelo setor de educação do Movimento dos Trabalhadores Rurais Sem Terra (MST) do estado do Paraná.

Concordamos com D’Ambrosio (2008), que afirma ser um grande equívoco na educação quando o professor não conhece o ambiente cultural dos estudantes, tomando como referência sua cultura, seu ambiente e suas experiências. Apresentamos, nesta pesquisa, o inventário da realidade como meio possível para superar tal desconhecimento.

O contexto vivenciado nesta pesquisa mostra que os sujeitos nela envolvidos não conheciam certos aspectos sobre a realidade local. Trata-se de duas escolas municipais localizadas nos Assentamentos Eli Vive I e Eli Vive II - que chamaremos, aqui, de Assentamento Eli Vive -, no município de Londrina, Paraná.

No ano de 2017, foi desenvolvido um curso de formação de professores dessas duas escolas, como uma parceria entre a Universidade Tecnológica Federal do Paraná (UTFPR) e a Secretaria Municipal de Educação de Londrina (SME). O curso abordava alguns aspectos da Educação do Campo. Após uma apresentação a respeito do inventário, os participantes do curso sugeriram - por não haver um documento organizado e atualizado sobre a realidade de seu entorno - que, no ano de 2018 , fosse desenvolvido um curso para que os profissionais das escolas pudessem construí-lo coletivamente - o que, de fato, aconteceu no ano em questão.

Compartilhamos com Sachs (2019) a compreensão de que o inventário da realidade é uma forma de proporcionar aos profissionais da Educação do Campo maior conhecimento sobre o ambiente, a história e a realidade dos estudantes e das comunidades às quais eles pertencem. 
Este artigo tem como objetivo apresentar o processo de construção coletiva do inventário da realidade por profissionais de duas escolas do campo, localizadas em assentamentos da reforma agrária; problematizar essa construção; e discutir os resultados obtidos. Os pressupostos da pesquisa-ação nortearam esse caminho, considerando que a demanda pelo inventário da realidade veio da própria comunidade escolar, que, coletivamente, trabalhou em sua construção, contando, para isso, com a ação, a organização e o planejamento das pesquisadoras, que auxiliaram em todo o processo.

\section{Educação do Campo e o Inventário da Realidade}

Nesta seção, apresentamos o que é o inventário da realidade, que teve papel central nesta pesquisa, mas, para isso, é necessário que ele seja contextualizado como parte de uma proposta maior de Educação do Campo. Por essa razão, iniciamos tratando da Educação do Campo, em linhas gerais, e, na sequência, da proposta do MST do Paraná para as escolas do campo em áreas de reforma agrária. Desse modo, o inventário da realidade pode ser apresentado, descrito e mais bem-discutido posteriormente.

A Educação do Campo tem um histórico atrelado ao protagonismo dos movimentos sociais no Brasil, em especial o MST - que se caracteriza como um movimento brasileiro de luta pela reforma agrária. No MST, há grande preocupação com a educação, visto que ela constitui suporte para a luta pela reforma agrária e pilar para a transformação social. Nesse sentido, Kolling, Nery e Molina vêm corroborar a importância da educação para o movimento, pois:

Não basta ter escolas no campo; quer-se ajudar a construir escolas do campo, ou seja, escolas com um projeto político-pedagógico vinculado às causas, aos desafios, aos sonhos, à história e à cultura do povo trabalhador do campo (1999, p. 18, grifos dos autores).

Desde a constituição da concepção de Educação do Campo, no fim dos anos 1990, ela enfrenta muitos desafios, pois se constitui no movimento de combate a certas concepções de educação e de sociedade, assim como de interpretações da realidade. Nesse sentido, a Educação do Campo nos remete aos "pilares da pedagogia moderna mais radicalmente emancipatória, de base socialista e popular e de referencial teórico marxista" (CALDART, 2009, p. 42).

No âmbito do estado do Paraná, as articulações referentes à Educação do Campo começaram a tomar corpo após algumas políticas ocorridas em âmbito nacional. Assim, destacamos como primeiro marco a criação da Coordenação Estadual da Educação do Campo, vinculada à Secretaria de Estado da Educação (SEED), no ano de 2003.

Durante o ano de 2003, foram realizadas audiências com o governador do estado e reuniões com o Conselho Estadual de Educação para serem criadas oficialmente as escolas itinerantes em âmbito estadual situadas em acampamentos da reforma agrária, que podem mudar sua localização junto com o acampamento (por isso, a itinerância). Em 17 de fevereiro de 2004, foi lançada a Resolução n. 614, da Secretaria de Estado da Educação, reconhecendo as escolas itinerantes como "experiências pedagógicas" por dois anos, renovados posteriormente para outros três. A aprovação definitiva ocorreu em 2008.

Além das políticas públicas do governo estadual para a educação, o MST do Paraná, como movimento social, possui uma proposta pedagógica para escolas situadas em áreas de reforma agrária - seja em acampamentos (que são provisórios), seja em assentamentos (que são permanentes) - com o objetivo de promover uma educação escolar ligada ao projeto de desenvolvimento social e econômico que o Movimento defende. 
No ano de 2009, o MST do Paraná, contando com a participação de educadores da educação básica e de professores de algumas universidades, elaborou cadernos para registrar as experiências vividas em suas escolas. Por meio dessa ação, houve a percepção da necessidade de certas mudanças, no sentido de melhorar o que já estava sendo feito, principalmente no que tange ao planejamento das atividades pedagógicas a partir de questões da realidade e à inclusão da autonomia dos estudantes nos processos de autogestão. Assim, em 2010, com a participação de Luiz Carlos de Freitas e Roseli Salete Caldart, o movimento passou a reelaborar sua proposta pedagógica, iniciando sua implementação em 2013, com o denominado Plano de Estudos das Escolas Itinerantes do Paraná (MST, 2013).

Ficou evidente que, para sustentar essa proposta pedagógica, seria necessário um conhecimento geral da realidade do entorno das escolas, principalmente para a criação dos complexos de estudo, que são, em linhas gerais, unidades curriculares interdisciplinares desenvolvidas a partir de porções da realidade. A construção do inventário da realidade para a criação dos complexos mostra-se necessária e indispensável, pois esse instrumento tem o potencial de indicar as porções da realidade relevantes para aquele contexto. O inventário, nessa perspectiva, é um documento no qual se apresenta um registro organizado de aspectos materiais ou imateriais da comunidade camponesa.

Nesse sentido, Hammel, Farias e Sapelli (2015) indicam a importância de a escola se aproximar das questões da comunidade em que está inserida, contemplando lutas e formas de organização e trabalho. "Se partirmos do pressuposto de que a realidade é um instrumento fundamental para a formação dos sujeitos, ela precisa ser apreendida por todos para que possa fundamentar o processo pedagógico vinculado às questões da atualidade" (HAMMEL; FARIAS; SAPELLI, 2015, p. 73). O inventário da realidade é uma possibilidade para isso.

No Paraná, esse movimento de construção de inventários teve início por volta do ano de 2010, nas escolas em áreas de reforma agrária. Essas escolas conseguiram elaborar o inventário estabelecendo um roteiro, com questões sobre os diversos componentes que faziam parte da vida da comunidade e de questões no âmbito das próprias escolas. Já no ano de 2016, foi elaborado um guia metodológico para a construção do inventário da realidade pelas escolas do campo (CALDART et al., 2016).

Esse guia propõe uma divisão em sete blocos temáticos, sendo necessário, para constituir um inventário, pelo menos os dados básicos em cada um deles e ficando a cargo da equipe responsável pela elaboração dosar a quantidade de informações dos blocos, segundo a realidade que se apresenta. Para a coleta de dados de um inventário, podem ser usadas as mais variadas estratégias: questionários, registros em fotografias, em vídeos, entrevistas, entre outras.

O inventário da realidade nas escolas em área de reforma agrária se mostra uma potencialidade nas condições de atividade e produto (SACHS, 2019). Como atividade, pois "a construção do inventário exige e possibilita o envolvimento daqueles que o fazem com toda a comunidade: estudantes das escolas, pais e responsáveis, equipe escolar e demais moradores" (SACHS, 2019, p. 44-45). As pessoas participantes precisam conhecer mais sobre o entorno da escola e as características sociais, culturais e econômicas da vida ali. Nem sempre os profissionais das escolas têm contato mais próximo com o que foge ao âmbito puramente pedagógico. Também como produto, pois "é uma ferramenta de trabalho para materializar sua ligação com a vida e as relações sociais de que é parte” (CALDART et al., 2016, p. 1). A disponibilização, de modo acessível, do inventário construído para os profissionais das escolas é necessária para isso.

Assim, é de extrema relevância que as escolas nessas áreas realizem esse movimento de construção do inventário, o qual pode nortear sua proposta pedagógica de maneira geral e o trabalho dos professores de maneira mais específica.

Cabe salientar que, apesar de proposto inicialmente para escolas em áreas de reforma agrária, o inventário da realidade poderia ser construído em diferentes contextos; porém, em escolas que recebam 
estudantes de diferentes áreas (sejam rurais ou urbanas) haveria maior dificuldade de delimitar qual o entorno a ser considerado nas pesquisas, que não poderia se restringir ao entorno da escola, mas deveria abranger também as residências desses estudantes. No caso de assentamentos e acampamentos, essas áreas coincidem - o que facilita o trabalho.

\section{Pesquisa-ação}

O produto desta pesquisa - o inventário da realidade de duas escolas do campo -, da maneira como foi concebido, ou seja, oriundo da demanda levantada pelo grupo formado por profissionais das duas escolas, remete-nos aos estudos realizados por Thiollent sobre pesquisa-ação:

A pesquisa-ação é um tipo de pesquisa social com base empírica que é concebida e realizada em estreita associação com a resolução de um problema coletivo e no qual os pesquisadores e os participantes representativos da situação ou do problema estão envolvidos de modo cooperativo ou participativo (1986, p. 14).

A pesquisa-ação, como pesquisa participativa, assume a função de diagnosticar uma situação, iniciar a ação e fazer o devido acompanhamento, desencadeando novas ações, com a intenção de mudar uma determinada realidade social, proporcionando, assim, benefícios aos envolvidos no processo.

Podemos dividir o processo de pesquisa-ação em quatro principais etapas, quais sejam: fase exploratória, fase principal, fase de ação e fase de avaliação (THIOLLENT, 1997).

A fase exploratória consiste em determinar campo de pesquisa, interessados e suas expectativas e estabelecer um primeiro levantamento (ou "diagnóstico") da situação, dos problemas prioritários e eventuais ações. No caso da pesquisa aqui apresentada, a fase exploratória deu-se no ano de 2017, quando os participantes do curso "Educação Matemática do Campo" fizeram um levantamento das informações que havia no Assentamento Eli Vive sobre a realidade do entorno das escolas, tendo sido identificada por eles a necessidade de uma atualização; o inventário da realidade foi uma demanda da própria comunidade escolar.

Após a fase exploratória, em que é feito o diagnóstico do problema, começa-se a pensar no tema da pesquisa. Dessa maneira, após a verificação da falta de um documento atualizado da realidade do entorno das escolas, no ano de 2018, foi planejada a continuação do curso, para todos os professores e gestores das duas escolas municipais, com o objetivo de construir coletivamente o inventário da realidade. O curso foi intitulado "Educação do Campo e a Construção do Inventário da Realidade".

Como já apresentamos anteriormente, o inventário da realidade em escolas em áreas de reforma agrária tem papel fundamental para o estabelecimento de diretrizes para o ensino. Assim, o tema da pesquisa apresentou-se, de maneira inicial, do seguinte modo: a construção coletiva do inventário da realidade por profissionais de duas escolas do campo, localizadas em assentamentos da reforma agrária.

Após o estabelecimento do problema, na pesquisa-ação, passamos para a fase principal, ou seja, a fase em que há um claro diagnóstico sobre a realidade e os pontos que se deseja pesquisar em conjunto com os participantes; os pesquisadores iniciam, assim, a prática. Nessa fase, também há a definição dos temas e dos problemas prioritários a ser investigados - são hipóteses de pesquisa. Ainda segundo Thiollent (1997), a fase principal é composta por um grande conjunto de entrevistas individuais e coletivas ou questionários aplicados a pessoas-chave.

No caso da nossa pesquisa, essa fase principal começa desde antes do primeiro encontro do curso de 2018. Contudo, somente a partir dele pudemos ter um panorama das pessoas que estariam envolvidas no 
curso naquele ano e o que conheciam sobre a temática a ser pesquisada. Verificamos, então, que seria necessário pensar em uma logística na qual todos pudessem participar, já que o curso aconteceria em uma das escolas e no horário de trabalho de todos.

A fase de ação, que é a terceira etapa da pesquisa-ação, é o momento de desenvolver atitudes que possam resolver o problema ou a demanda levantada pelo grupo - em outras palavras, é o momento da prática. A ação corresponde ao que precisa ser feito (ou transformado) para realizar a solução do problema. No caso da nossa pesquisa, a ação deu-se durante todo o curso, pois os participantes começaram, desde o segundo encontro, a pesquisar a respeito das informações solicitadas no guia metodológico (CALDART et al., 2016) para compor o inventário da realidade.

Por fim, temos a fase de avaliação, em que os dados levantados são analisados e interpretados. No nosso caso, os dados produzidos durante o curso serviram para compor o inventário da realidade das escolas. Essa avaliação foi feita primeiro pelos participantes da pesquisa, em um momento final de socialização, e por nós, ao organizarmos as informações no documento final. No relato da pesquisa, apresentamos algumas indicações de itens que poderiam ser mais bem-explorados, investigados e documentados.

Como este trabalho trata da solução de um problema coletivo, tendo como ponto central o agir participativo e a ação coletiva, consideramos que o produto da pesquisa - no caso, o inventário da realidade - opera de acordo com os pressupostos da pesquisa-ação em um contexto de pesquisa participativa.

\section{Desenvolvimento}

Esta pesquisa foi realizada no Assentamento Eli Vive, no município de Londrina, Paraná, com profissionais de duas escolas do campo que, no ano de 2017, demandaram a construção do inventário da realidade. Isso aconteceu, mais especificamente, nos últimos dois meses de um curso, quando foi apresentado ao grupo o inventário que havia sido desenvolvido até o ano de 2014 e, com isso, foi possível analisar o que já estava feito, o que precisava ser atualizado e o que ainda estava por fazer.

O grupo solicitou que o inventário da realidade fosse construído com tempo necessário para isso, de um modo coletivo e organizado. Dessa maneira, foi proposto um curso para os profissionais das duas escolas municipais, a fim de construírem, durante o ano de 2018, o inventário da realidade.

Thiollent (1986) defende que uma pesquisa concebida por necessidade de resolução de um problema coletivo e na qual há a participação efetiva de pesquisadores e participantes da comunidade onde o problema está inserido está de acordo com os pressupostos da pesquisa-ação.

Por isso, no ano de 2018, o curso começa a trilhar no sentido de tornar possível que aquele grupo pudesse construir um novo inventário da realidade, a partir de um documento já existente, o qual viesse a corresponder à realidade do entorno das escolas. Essa era uma demanda não só dos participantes do curso, mas também daqueles que estavam, de uma maneira ou de outra, envolvidos com as escolas do Assentamento Eli Vive ${ }^{1}$.

Participaram do curso², então, quinze pessoas, sendo doze professores dos anos iniciais do Ensino Fundamental, dois diretores das escolas e uma trabalhadora de serviços gerais e moradora do Assentamento Eli Vive. Na Tabela 1, apresentamos a codificação utilizada no texto para identificar os participantes e algumas informações sobre eles, referentes ao cargo e ao local de trabalho, aos contratos de trabalho e à condição ou não de assentados. 
Tabela 1. Participantes do curso "Educação do Campo e a Construção do Inventário da Realidade"

\begin{tabular}{|c|c|c|c|c|}
\hline Código & Local de trabalho & $\begin{array}{l}\text { Cargo que } \\
\text { ocupa }\end{array}$ & $\begin{array}{l}\text { Contrato de } \\
\text { Trabalho }\end{array}$ & Característica adicional \\
\hline P01 & $\begin{array}{c}\text { Escola estadual do Assentamento } \\
\text { Eli Vive I }\end{array}$ & $\begin{array}{l}\text { Trabalhadora de } \\
\text { serviços gerais }\end{array}$ & $\begin{array}{l}\text { Funcionária } \\
\text { terceirizada }\end{array}$ & $\begin{array}{c}\text { Moradora do } \\
\text { Assentamento Eli Vive I }\end{array}$ \\
\hline P02 & $\begin{array}{c}\text { Escola municipal do Assentamento } \\
\text { Eli Vive II } \\
\end{array}$ & Diretora & Concurso público & Não assentada \\
\hline P03 & $\begin{array}{l}\text { Escola municipal do Assentamento } \\
\text { Eli Vive II }\end{array}$ & Professora & Temporário & $\begin{array}{c}\text { Moradora do } \\
\text { Assentamento Eli Vive II }\end{array}$ \\
\hline P04 & $\begin{array}{l}\text { Escola municipal do Assentamento } \\
\text { Eli Vive II }\end{array}$ & Professora & Concurso público & $\begin{array}{c}\text { Moradora do } \\
\text { Assentamento Eli Vive II }\end{array}$ \\
\hline P05 & $\begin{array}{l}\text { Escola municipal do Assentamento } \\
\text { Eli Vive II }\end{array}$ & Professor & Concurso público & $\begin{array}{l}\text { Morador do } \\
\text { Assentamento Eli Vive II }\end{array}$ \\
\hline P06 & $\begin{array}{l}\text { Escola municipal do Assentamento } \\
\text { Eli Vive I }\end{array}$ & Professor & Concurso público & $\begin{array}{c}\text { Morador do } \\
\text { Assentamento Eli Vive I }\end{array}$ \\
\hline P07 & $\begin{array}{l}\text { Escola municipal do Assentamento } \\
\text { Eli Vive I }\end{array}$ & Professora & Temporário & Não assentada \\
\hline P08 & $\begin{array}{c}\text { Escola municipal do Assentamento } \\
\text { Eli Vive I }\end{array}$ & Professor & Concurso público & Não assentado \\
\hline P09 & $\begin{array}{c}\text { Escola municipal do Assentamento } \\
\text { Eli Vive I } \\
\end{array}$ & Professor & Temporário & Não assentado \\
\hline P10 & $\begin{array}{l}\text { Escola municipal do Assentamento } \\
\text { Eli Vive I }\end{array}$ & Professora & Temporário & Não assentada \\
\hline P11 & $\begin{array}{l}\text { Escola municipal do Assentamento } \\
\text { Eli Vive I }\end{array}$ & Professora & Temporário & Não assentada \\
\hline P12 & $\begin{array}{l}\text { Escola municipal do Assentamento } \\
\text { Eli Vive I }\end{array}$ & Diretor & Concurso público & Não assentado \\
\hline P13 & $\begin{array}{l}\text { Escola municipal do Assentamento } \\
\text { Eli Vive I }\end{array}$ & Professora & Temporário & Não assentada \\
\hline P14 & $\begin{array}{l}\text { Escola municipal do Assentamento } \\
\text { Eli Vive I }\end{array}$ & Professora & Concurso público & $\begin{array}{c}\text { Moradora do } \\
\text { Assentamento Eli Vive I }\end{array}$ \\
\hline P15 & $\begin{array}{l}\text { Escola municipal do Assentamento } \\
\text { Eli Vive I }\end{array}$ & Professora & Temporário & Não assentada \\
\hline
\end{tabular}

Fonte: Elaboração própria.

Assim, dos quinze participantes, três eram moradores do Assentamento Eli Vive I e três, moradores do Assentamento Eli Vive II - ou seja, do total de participantes do curso, $40 \%$ eram caracterizados por participantes residentes no Assentamento Eli Vive, enquanto $60 \%$ eram caracterizados por participantes não assentados. Além disso, a respeito dos contratos de trabalho, uma participante era funcionária contratada por uma empresa terceirizada de serviços gerais, sete vinham de concurso público e outros sete tinham contratos temporários.

Os encontros do curso ocorreram em uma das escolas, entre os meses de abril e novembro de 2018, totalizando nove encontros presenciais, como consta na Tabela 2. Os encontros foram pré-agendados e alguns eram realizados em dias de formação pedagógica para os professores, conforme calendário da Secretaria Municipal de Educação de Londrina. Nesses dias, não havia alunos na escola e todos os profissionais podiam participar. Outros aconteceram em dias letivos, nos quais os professores precisavam estar em sala. Por isso, foi necessário separar os participantes em dois grupos - assim, no dia em que um grupo estava participando do curso, o outro grupo cobria o atendimento às turmas desses professores e vice-versa. 
Tabela 2. Planejamento do curso "Educação do Campo e a Construção do Inventário da Realidade"

\begin{tabular}{|c|c|}
\hline Data & Atividades planejadas \\
\hline $30 / 04 / 2018$ & $\begin{array}{c}\text { Todos os participantes } \\
\text { Apresentação. } \\
\text { Planejamento das atividades (leituras e construção do inventário). }\end{array}$ \\
\hline $21 / 05 / 2018$ & $\begin{array}{l}\text { Grupo } 1 \\
\text { Atividades de discussão sobre leituras e divisão de tarefas. }\end{array}$ \\
\hline $18 / 06 / 2018$ & $\begin{array}{c}\text { Grupo } 2 \\
\text { Atividades de discussão sobre leituras e divisão de tarefas. }\end{array}$ \\
\hline $23 / 07 / 2018$ & $\begin{array}{l}\text { Todos os participantes } \\
\text { Socialização e discussão sobre os primeiros resultados. }\end{array}$ \\
\hline $03 / 09 / 2018$ & $\begin{array}{c}\text { Grupo } 2 \\
\text { Socialização e discussão. }\end{array}$ \\
\hline $24 / 09 / 2018$ & $\begin{array}{c}\text { Grupo } 1 \\
\text { Socialização e discussão. }\end{array}$ \\
\hline $22 / 10 / 2018$ & $\begin{array}{c}\text { Grupo } 2 \\
\text { Socialização e discussão. }\end{array}$ \\
\hline $12 / 11 / 2018$ & $\begin{array}{c}\text { Grupo } 1 \\
\text { Socialização e discussão. }\end{array}$ \\
\hline $30 / 11 / 2018$ & $\begin{array}{l}\text { Todos os participantes } \\
\text { Socialização do inventário da realidade. }\end{array}$ \\
\hline
\end{tabular}

Fonte: Elaboração própria.

Dentro dos dois grupos, que chamamos grupo 1 e grupo 2, os participantes se separaram em subgrupos, pois o guia metodológico para a construção do inventário da realidade (CALDART et al., 2016), utilizado no desenvolvimento do curso, divide-se em vários subtópicos. Ao todo, formaram-se seis subgrupos - que chamamos 1.1, 1.2, 1.3, 2.1, 2.2 e 2.3 -, com dois ou três participantes cada. Também, com grupos menores (de duas ou três pessoas, em vez de sete ou oito), entendemos que o trabalho poderia ser mais proveitoso e eficiente.

Os participantes organizaram-se de maneira que houvesse representantes das duas escolas - e, consequentemente, do Assentamento Eli Vive I e do Assentamento Eli Vive II - em cada grande grupo e também nos subgrupos. Essa organização foi pensada para que fossem consideradas as informações de toda a comunidade atendida pelas escolas. Como os Assentamentos Eli Vive I e II são um pouco distantes, algumas informações poderiam ser diferentes. Uma participante, P14, fez, no início do curso, um comentário a esse respeito:

P14: "No geral, acredito que se contemplem os dois [assentamentos], mas que tem algumas perguntas que serão específicas [da outra escola], né? Quantos alunos, quantos professores, como ela foi se constituindo. Eu acredito que separar o grupo para contar essa história também, depois que ela foi para lá, como que se organizou, acho que ficaria interessantíssimo, né?” (21/05/2018 - transcrição.)

A respeito dessa organização, podemos verificar a implementação da pesquisa-ação. $O$ fato de os participantes estarem engajados nesse primeiro passo do processo, o qual antecederia suas primeiras ações referentes à pesquisa a ser feita por eles, remete-nos à descrição de Thiollent sobre essa metodologia:

[...] podemos captar informações geradas pela mobilização coletiva em torno de ações concretas que não seriam alcançáveis nas circunstâncias da observação passiva. Quando as pessoas estão 
fazendo alguma coisa relacionada com a solução de um problema seu, há condição de estudar este problema num nível mais profundo e realista do que no nível opinativo ou representativo no qual se reproduzem apenas imagens individuais e estereotipadas (1986, p. 44).

O guia metodológico para a construção do inventário da realidade propõe divisão em blocos:

As informações a serem levantadas estão indicadas por blocos. A depender dos objetivos discutidos em cada escola, um bloco poderá ser mais detalhado do que outro, mas é muito importante ter dados básicos em todos os blocos, porque eles se referem a diferentes dimensões da vida com a qual o trabalho pedagógico da escola precisa ser conectado. A ordem dos levantamentos ou se eles serão feitos todos de uma vez é uma decisão do planejamento de cada escola (CALDART et al., 2016, p. 3).

Esses blocos se parecem com informações censitárias sobre diversos assuntos - mas, mais que trazer dados estatísticos da realidade, têm como objetivo fazer um retrato dela. Os blocos sugeridos são: 1) Recursos Naturais: (re)conhecendo a biodiversidade; 2) Pessoas/famílias que compõem a comunidade da escola: características de constituição, aspectos sociais, econômicos e culturais; 3) Produção: sistemas produtivos e uso de tecnologias; 4) Formas de trabalho e sua organização; 5) Lutas sociais e formas de inserção e organização política das famílias; 6) Escola: estrutura física, formas de organização do trabalho e aspectos curriculares; e 7) O que fazem crianças e jovens no tempo em que não estão na escola (CALDART et al., 2016).

Desse modo, no decorrer do curso, os participantes recebiam algumas atribuições, que diziam respeito a levantar os dados referentes à comunidade, a partir dos blocos descritos. A divisão se deu de acordo com a Tabela 3.

Tabela 3. Organização dos participantes em subgrupos

\begin{tabular}{cccc}
\hline Grupo & Subgrupo & Participantes & \multicolumn{1}{c}{ Blocos } \\
\cline { 2 - 4 } & Subgrupo 1.1 & P03, P10, P14 & Parte do Bloco 2 e Bloco 1 \\
\cline { 2 - 4 } & Subgrupo 1.2 & P05, P09 & Parte do Bloco 2 e Bloco 3 \\
\cline { 2 - 4 } & Subgrupo 1.3 & P04, P13 & Parte do Bloco 2 e Bloco 4 \\
\cline { 2 - 4 } Sut & Subgrupo 2.1 & P06, P12, P15 & Parte do Bloco 2 e Bloco 5 \\
\cline { 2 - 4 } & Subgrupo 2.2 & P07, P11 & Parte do Bloco 2 e Bloco 6 \\
\cline { 2 - 4 } & Subgrupo 2.3 & P01, P08 & Parte do Bloco 2 e Bloco 7 \\
\hline
\end{tabular}

Fonte: Elaboração própria.

Para a produção das informações, os participantes puderam utilizar entrevistas com estudantes, professores das escolas e membros do Assentamento Eli Vive, além de relatos orais, escritos, questionários fechados, consultas a documentos e registros fotográficos. Combinamos que a organização final do inventário da realidade ficaria como tarefa nossa, das duas pesquisadoras; por isso, os subgrupos deveriam nos entregar aquilo que tivessem produzido.

Inicialmente, nos primeiros encontros, foi abordado apenas o Bloco 2 (“Pessoas/famílias que compõem a comunidade da escola: características de constituição, aspectos sociais, econômicos e culturais”), 
que, por ser o mais extenso de todos, foi dividido entre os seis subgrupos. Na Tabela 4, estão os temas presentes nas questões do guia metodológico para a construção do inventário da realidade para o Bloco 2, já com a divisão entre os subgrupos.

Tabela 4. Temas das questões do Bloco 2

\begin{tabular}{cc}
\hline Subgrupo & Temas das questões \\
\hline Subgrupo 1.1 & $\begin{array}{c}\text { Quantidade de famílias, origem, etnia e composição; pessoas com deficiência; características } \\
\text { econômicas, sociais, culturais das famílias, relações de gênero e relações entre famílias. }\end{array}$ \\
\hline
\end{tabular}

Subgrupo 1.2 Moradias e entorno; acesso a luz elétrica, saneamento e água; meios de comunicação e de transporte.

Subgrupo $1.3 \quad$ Atividades de lazer, festas tradicionais, religiões, grupos artísticos, museus e bibliotecas.

Subgrupo 2.1 Alimentos: hábitos, origem, características, receitas; saúde: doenças, tratamentos e atendimento.

Subgrupo 2.2 Lixo; escolarização alfabetização e espaços educativos.

Subgrupo $2.3 \quad$ Renda monetária e agrícola; acesso a políticas públicas; dívidas.

Fonte: Adaptada de Caldart et al. (2016).

Assim, nos primeiros meses de curso, todos os subgrupos ficaram responsáveis por partes do Bloco 2. No mês de julho, após se passarem quase três meses de curso e três encontros, havia sido agendado um encontro em dia de prática pedagógica, no qual todos os participantes estariam presentes e apresentariam o que possuíam a respeito do Bloco 2.

O subgrupo 1.1 não havia conseguido muitos resultados sobre o número de famílias da comunidade, de onde vieram, a que etnias pertenciam, como eram compostas, quais eram suas principais características econômicas, a existência de pessoas portadoras de necessidades especiais na comunidade, entre outras questões. Relataram ter enviado um questionário aos dirigentes das brigadas ${ }^{3}$, mas que não tiveram retorno. Levaram alguns resultados que já tinham, fruto do Trabalho de Conclusão de Curso de uma das integrantes em um curso de especialização. A participante P14 indicou que, em breve, teria mais informações:

P14: "Eu acredito que tenha retorno agora nessa semana, né? Aí, assim, das questões que a gente encaminhou, algumas perguntas... já tinha alguma coisa feita. Eu tenho já algumas coisas digitalizadas e manda para você, né? [...] Foi isso, assim, a gente não fez muita, não teve muito retorno também" (23/07/2018 - transcrição).

O subgrupo 1.2 ficou responsável pelas informações das moradias, dos móveis e eletrodomésticos, do acesso a energia elétrica, saneamento e água, do levantamento das formas de acesso à informação, os transportes utilizados e como eram as estradas. Esse subgrupo, até a data da apresentação, em 23 de julho, havia apenas levantado algumas informações referentes ao Assentamento Eli Vive II, que foram apresentadas por um relato escrito a mão pelo professor desse subgrupo. Havíamos sugerido ao subgrupo adicionar registros fotográficos ao relato, mas isso não aconteceu.

No que se refere ao Assentamento Eli Vive I, não tínhamos nenhuma informação, pois o professor havia elaborado um questionário e não havia conseguido entregar às pessoas que responderiam, como ele 
descreve a seguir. Foi proposto, naquele dia de socialização, por outros participantes, que esse subgrupo entregasse o questionário para que os próprios alunos pudessem responder, mas isso deveria ser feito com aqueles de $4^{\circ}$ ou $5^{\circ}$ ano do Ensino Fundamental - pois os mais novos poderiam não saber responder a algumas questões.

P09: “Eu não me senti bem para fazer esses questionamentos às famílias daqui, eu tentei fazer... até fiz o questionário, mas como tinha muitas pessoas entregando para os alunos, ia dar um congestionamento de papel. Entrevistá-los e fazer esse tipo de pergunta, eu não me senti à vontade de fazer. Eu fiz um questionário com perguntas fechadas, onde ele poderia colocar x" (23/07/2018 - transcrição).

O subgrupo 1.3 era responsável pelas informações sobre as atividades de lazer da comunidade, das festas tradicionais, das igrejas e religiões existentes no Assentamento e se existiam grupos artísticos e acesso a produções artísticas no local.

Para realizarem a pesquisa, enviaram questionários pelas crianças, com duas questões, uma sobre as atividades de lazer e outra sobre as igrejas e religiões. Também, enviaram um questionário a um participante do grupo musical Geração Nativa, perguntando como funcionava esse grupo artístico - segundo os participantes do curso, o único no Assentamento Eli Vive. Por fim, enviaram questionários para duas pessoas assentadas, para obterem outras informações.

Assim, fizeram um resumo das informações que conseguiram levantar e nos entregaram, neste encontro de socialização, os questionários respondidos por alguns alunos do Assentamento Eli Vive I. A participante, membro desse subgrupo, que ficou responsável pelas informações referentes ao Assentamento Eli Vive II não esteve presente nesse dia.

O subgrupo 2.1 ficou responsável pelos dados sobre os hábitos alimentares das famílias, os alimentos produzidos, os problemas de saúde mais comuns entre as famílias, como eram feitos os atendimentos de saúde e a existência de postos de saúde próximos à comunidade. Nesse dia de apresentação, os membros do subgrupo revelaram que não fizeram visita à comunidade, mas que enviaram cinquenta questionários para os alunos do Ensino Médio ${ }^{4}$, para que fossem respondidos pelas famílias sobre esses tópicos. Até aquela data, eles tinham recebido dez questionários respondidos apenas.

O subgrupo 2.2 deveria fazer um levantamento da média de escolarização das famílias, se havia analfabetos no assentamento, a distância entre as moradias e a escola e algumas informações sobre o lixo. Esse subgrupo entrevistou alguns pais de alunos no dia da reunião escolar e mandou, por meio dos alunos, um questionário sobre a escolarização dos familiares. Ao todo, obtiveram dados de escolarização de 145 pessoas. Uma das participantes de subgrupo não estava presente no dia da apresentação, mas comprometeu-se a repassar às pesquisadoras os documentos obtidos. Sua companheira no subgrupo compartilhou um pouco sobre a questão do lixo no Assentamento Eli Vive I. O subgrupo entregou um questionário sobre esse tema para as crianças e conversou com dez alunos do $5^{\circ}$ ano do Ensino Fundamental. Elas disseram que pensaram em gravar a entrevista, mas, por não saberem se haveria necessidade de pedir autorização, resolveram apenas anotar as respostas. Importante destacar que, nesse subgrupo, não havia ninguém que trabalhasse ou morasse no Assentamento Eli Vive II.

Por fim, o subgrupo 2.3 ficou responsável por levantar as fontes de renda das famílias, se havia acesso a políticas públicas ou programas de financiamento e algumas informações sobre as dívidas das famílias. Os membros optaram por fazer visita a três casas da comunidade e entrevistar essas famílias. P01 explica como foi isso: 
P01: "Eu optei em fazer entrevista, em ir a pé... E fui muito bem recebida, e as famílias me responderam a realidade deles. Disse que era para a escola, que vai constar no PPP da escola... que, futuramente, se eles quiserem ter acesso ao PPP, vai constar e vai estar aberto para eles lerem. E aí, o que é PPP? Aí eu fui explicar... [...] O carro-chefe dessas famílias é a produção de leite... O Bolsa Família é renda mensal, mandioca é renda anual" (23/07/2018 - transcrição).

Ao final do encontro desse dia, pudemos ter um panorama de como estavam os dados para o inventário da realidade, pelo menos no que se referia ao Bloco 2, além de termos ideia das estratégias adotadas e dificuldades enfrentadas.

Na sequência, no mês de setembro, foi feita uma divisão entre os demais blocos para todos os subgrupos, como consta na Tabela 3.

Os três subgrupos do grupo 1 foram assim organizados: o subgrupo 1.1 ficou responsável pelos itens que diziam respeito ao Bloco 1: "Recursos Naturais: (re)conhecendo a biodiversidade"; o subgrupo 1.2, pelo Bloco 3: "Produção: sistemas produtivos e uso de tecnologias"; e o subgrupo 1.3, pelo Bloco 4: "Formas de trabalho e sua organização".

Quanto ao grupo 2, a divisão foi a seguinte: o subgrupo 2.1 ficou responsável pelos tópicos do Bloco 5: "Lutas sociais e formas de inserção e organização política das famílias"; o subgrupo 2.2 se responsabilizou pelo Bloco 6: "Escola: estrutura física, formas de organização do trabalho e aspectos curriculares"; e o subgrupo 2.3 pelo Bloco 7: "O que fazem crianças e jovens no tempo em que não estão na escola”.

Procedemos com os demais blocos nos mesmos moldes do que foi feito para o Bloco 2. Nos encontros que se seguiram, os subgrupos planejaram as estratégias de coleta de dados, entregaram-nos e socializaram com uma parte dos integrantes o que haviam coletado, as estratégias e as dificuldades encontradas.

Os temas presentes nas questões do guia metodológico (CALDART et al., 2016), que auxiliaram na organização dos subgrupos, estão presentes na Tabela 5.

Tabela 5. Temas das questões dos Blocos 1, 3, 4, 5, 6 e 7

\begin{tabular}{|c|c|}
\hline Subgrupo & Temas das questões dos blocos \\
\hline Subgrupo 1.1 & $\begin{array}{l}\text { Bloco 1: Recursos Naturais: (re)conhecendo a biodiversidade } \\
\text { Vegetação; reservas; animais; relevo; características do solo; } \\
\text { indicadores para agricultura; clima; fontes de água. }\end{array}$ \\
\hline Subgrupo 1.2 & $\begin{array}{l}\text { Bloco 3: Produção: sistemas produtivos e uso de tecnologias } \\
\text { Acesso à terra; cultivos; animais de criação; processamento de produtos; agroindústria; } \\
\text { atividades extrativistas; artesanato; indústrias; } \\
\text { maquinários e ferramentas; resultados da produção; assistência técnica. }\end{array}$ \\
\hline Subgrupo 1.3 & $\begin{array}{l}\text { Bloco 4: Formas de trabalho e sua organização } \\
\text { Divisão e organização do trabalho; trabalho doméstico. }\end{array}$ \\
\hline Subgrupo 2.1 & $\begin{array}{l}\text { Bloco 5: Lutas sociais e formas de inserção e organização política das famílias } \\
\text { Movimentos sociais; organizações de trabalhadores; } \\
\text { sindicatos; cooperativas; entidades; igrejas; grupos culturais. }\end{array}$ \\
\hline Subgrupo 2.2 & $\begin{array}{l}\text { Bloco 6: Escola: estrutura física, formas de organização do trabalho e aspectos curriculares } \\
\text { Infraestrutura; educadores; estudantes; organização do trabalho; gestão da escola; interação com a } \\
\text { comunidade; referências para o ensino; planejamento pedagógico; alimentos da merenda escolar. }\end{array}$ \\
\hline Subgrupo 2.3 & $\begin{array}{c}\text { Bloco 7: O que fazem crianças e jovens no tempo em que não estão na escola } \\
\text { Participação nas atividades produtivas, nos trabalhos domésticos, em grupos ou } \\
\text { organizações entre si e com adultos, em atividades culturais e em jogos e brincadeiras; } \\
\text { outras atividades de lazer: TV, Internet, redes sociais, leitura. }\end{array}$ \\
\hline
\end{tabular}

Fonte: Adaptada de Caldart et al. (2016). 
Houve mais cinco encontros, dois com o grupo 2 (nos dias 3 de setembro e 22 de outubro), dois com o grupo 1 (24 de setembro e 12 de novembro) e a finalização do curso, quando houve socialização com todos os participantes, no dia 30 de novembro - como consta na Tabela 2.

A respeito das informações do Bloco 1, sobre os recursos naturais do Assentamento Eli Vive, a participante do subgrupo 1.1, professora e moradora do Assentamento Eli Vive II, enviou um questionário para um dos líderes das brigadas, que respondeu por meio de áudios pelo aplicativo WhatsApp. Sobre o Assentamento Eli Vive I, uma das participantes nos entregou dados geográficos retirados do site da prefeitura de Londrina. As informações não correspondiam à realidade do Assentamento Eli Vive, pois referiam-se à parte urbana do município de Londrina. Obtivemos resultados referentes a vegetação natural, plantas nativas, áreas de reserva do assentamento, características do solo e fontes de água.

Alguns desses dados, referentes ao Bloco 1, foram apresentados no dia da socialização final, em 30 de novembro, quando as participantes do subgrupo 1.1 conseguiram preparar uma apresentação com fotos e explicações. Alguns dos dados sobre as fontes das águas foram recebidos por nós posteriormente, em 2019, do diretor de uma das escolas.

Em relação ao Bloco 3, sobre sistemas produtivos e tecnologias utilizadas nos assentamentos, obtivemos apenas as informações referentes ao Assentamento Eli Vive I, pois o professor integrante do subgrupo 1.2 do Assentamento Eli Vive II deixou de frequentar os encontros. Em outra ocasião, ele já havia relatado que estava com dificuldade de conciliar os horários de aulas e de outros cursos promovidos pela Secretaria Municipal de Educação com os horários desse curso.

O professor responsável pelo subgrupo 1.2 trabalhou novamente com questionários, que foram entregues a funcionários da escola municipal onde atuava, os quais eram também assentados. O questionário era semiestruturado, com perguntas abertas e fechadas, e foi respondido pelos alunos mais velhos (dos anos iniciais do Ensino Fundamental) sozinhos ou com ajuda dos familiares. Sete pessoas responderam a dezenove perguntas. Alguns resultados foram obtidos a respeito de cultivos existentes nos lotes, origem das sementes, criação de animais, comercialização e consumo da produção, bem como outras informações sobre a produção, por exemplo sobre a não utilização de fertilizantes e agrotóxicos pela maioria. O professor afirma:

P09: “A divisão em subgrupos ficou bacana, mas eu não gostei de ter feito com alguém do Eli Vive II pela falta de comunicação [...]. Outra coisa: para conhecer a realidade, eu preciso ir até a realidade" (30/11/2018 - transcrição).

O Bloco 4, sobre as formas de trabalho e organização, responsabilidade do subgrupo 1.3, também ficou com algumas informações comprometidas. Eram duas professoras, uma de cada escola, mas os dados obtidos são todos referentes ao Assentamento Eli Vive II. Foi entregue um questionário, com seis perguntas abertas, aos alunos da escola onde atuavam as professoras e nove crianças devolveram-no respondido. Alguns dados são sobre as formas de organização do trabalho, como as associações, sobre a existência de trabalhadores assalariados e a divisão do trabalho com relação às atividades produtivas do lote no âmbito familiar.

As informações do Bloco 4 não foram socializadas no último dia do curso (30 de novembro), pois as duas integrantes organizaram-se de modo que uma delas apresentaria os resultados referentes ao Bloco 2 - desenvolvidos na primeira parte do curso - e a outra professora os resultados do Bloco 4, a qual não esteve presente na data.

Muitos alunos responderam às questões referentes ao Bloco 4 de maneira inconclusiva, pois as perguntas não estavam elaboradas de acordo com a compreensão de uma criança. Acreditamos que alguns deles não tenham sabido explicar corretamente algumas informações, como a do último tópico, acerca do modo de organização das famílias. P13 afirma, a esse respeito: 
P13: "Uma coisa que eu percebi, principalmente na parte do Bloco 4, foi que as questões eram muito complexas... Alguns retornavam e falavam que os pais não conseguiram entender" (30/11/2018 - transcrição).

No que tange ao Bloco 5, sobre as lutas sociais e as formas de organização, os integrantes do subgrupo 2.1 não nos entregaram nenhuma informação escrita; apenas apresentaram os resultados da pesquisa no dia da socialização. Nesse dia, eles prepararam um cartaz explicativo sobre o regimento interno do Assentamento Eli Vive, vinculado ao MST. Apresentaram, por exemplo, que, com a mudança de acampamento para assentamento, houve uma perda na participação das famílias no movimento social.

No Bloco 6, que tratava da escola, o subgrupo 2.2 organizou uma apresentação, no dia 30 de novembro em que mostrava os ambientes da escola municipal do Assentamento Eli Vive I, a qual compartilha seu espaço físico com a escola estadual. Infelizmente, não obtivemos informações referentes à outra escola municipal, pois não havia nenhum representante dessa escola no subgrupo e, pelo fato de as duas integrantes serem professoras da mesma escola e não assentadas, houve dificuldade de conseguir esses dados.

O Bloco 7 tratava do que as crianças fazem no período em que não estão na escola. Os participantes do subgrupo 2.3 realizaram uma pesquisa entre os alunos das duas escolas do Assentamento Eli Vive I, nos dias de curso com o grupo 2. Puderam constatar, por exemplo, que muitas crianças e muitos jovens ajudam no trabalho nos lares e na roça - seja na agricultura, seja na criação de animais - e que o tempo é utilizado, também, para realizar as tarefas escolares solicitadas pelos professores, além de atividades de lazer, como brincar, andar de bicicleta, assistir televisão e navegar na Internet.

No dia de encerramento do curso, havia quatro professoras temporárias recém-contratadas participando da socialização dos subgrupos. Uma das professoras novatas, ao final, quis compartilhar com o grupo sua impressão a respeito do que tinha presenciado:

"Para mim, que estou começando agora, como eu disse, faz pouco mais de quinze dias que estou vindo aqui, então esse pontapé inicial para mim foi muito interessante, achei bem legal, muito importante, porque tenho muitas dúvidas, muitas curiosidades, porque éum desafio, éum novo desafio"(30/11/2018 - transcrição).

\section{Discussão}

Diante do desenvolvimento relatado na seção anterior, apresentamos aqui uma discussão a respeito do processo de construção coletiva do inventário da realidade. Queremos indicar alguns aspectos que consideramos problemáticos e outros potenciais.

Ficou claro para nós, durante a pesquisa, que, mesmo seguindo um roteiro de questões presentes no guia metodológico para a construção do inventário da realidade (CALDART et al., 2016), não foi possível obter algumas informações que considerávamos importantes para o documento. A isso atribuímos alguns fatos que podem ter atrapalhado a produção de dados, indicados nos próprios encontros pelos participantes: distância das localidades no Assentamento Eli Vive (das escolas para os lotes ou outros locais); falta de tempo hábil para conseguir cumprir as atividades profissionais atreladas às atividades do curso (pois alguns profissionais ficavam o dia todo na escola, ministrando aulas nos períodos matutino e vespertino); falta de tempo entre um encontro e outro para realização das atividades propostas; período de férias, em que os participantes componentes dos subgrupos não se encontraram; além de outros motivos pessoais.

Além desses, outros fatores também contribuíram para que as informações do inventário da realidade ficassem, em alguma medida, frágeis e incompletas. 
A maioria dos subgrupos utilizou como estratégia questionários a ser respondidos pelos estudantes. Muitas respostas, assim, ficaram no nível de entendimento de uma criança ou de um adolescente. Não houve, por exemplo, o refinamento desse instrumento, com aplicações-piloto ou uma discussão entre os participantes dos grupos antes da explicação; os questionários foram elaborados e discutidos apenas dentro dos subgrupos. Entrevistas com as famílias e membros da comunidade poderiam ter sido mais exploradas - o que aconteceu em alguns casos.

Como sugestão dos próprios envolvidos ficou a ideia de estar em contato realmente com a realidade, visitar os lotes e as famílias; não apenas ficar preso aos questionários dentro das próprias escolas, para complementação das informações no inventário da realidade.

É interessante salientar que sempre que um dos participantes relatava uma dificuldade, logo em seguida era sugerido que o grupo pudesse dar alguma ideia a ele. Nós, pesquisadoras, colocamo-nos à disposição para emprestar câmera fotográfica e viabilizar transporte para alguma visita que quisessem fazer, por exemplo. Houve considerável colaboração entre os participantes -com a ajuda seja na entrega, seja no recolhimento de questionários, sugestões de pessoas a ser entrevistadas, mediação nesse processo, meios para obtenção de informações ou ideias de complementação de dados com registros fotográficos, mapas ou filmagens.

Também notamos que o tempo entre os encontros de um mesmo subgrupo - aproximadamente dois meses - não favoreceu a organização do trabalho, pois, diferentemente do que havíamos planejado, considerando que, nesse período, seria possível fazer a pesquisa e levar os resultados para o grupo, os participantes nos relatavam que não haviam tido muitos avanços e, então, um bom tempo já havia se passado.

Faltas e desistências de alguns participantes também comprometeram o levantamento de dados para o inventário.

Notamos, também, que, sem que nós indicássemos algo referente às informações faltantes, os próprios subgrupos perceberam que poderiam ter se envolvido mais na produção dos dados; porém alguns mostraram que tentaram ao máximo cumprir com o que tinha sido proposto.

Como se trata de uma pesquisa participativa, pautada na pesquisa-ação, em que os sujeitos foram responsáveis pelas ações, tomadas de decisão e levantamentos de dados, acreditamos que o produto, com seus limites e suas potencialidades, é o reflexo do contexto, da organização e da realidade por eles vivenciada. Trata-se de algo produzido por eles e com eles.

Algumas informações, organizadas posteriormente por nós, pesquisadoras, precisaram ser complementadas. Isso foi feito por meio de consultas aos próprios participantes, nos anos de 2019 e 2020 (quando foi finalizado o inventário da realidade), e pesquisas em trabalhos acadêmicos, mapas e sites de órgãos públicos.

A construção de um inventário da realidade em uma perspectiva coletiva não parece e nem é uma tarefa fácil. Ao longo do caminho, apresentam-se inúmeros empecilhos e situações difíceis. Percebemos que, apesar de ser uma demanda da própria comunidade, é uma tarefa bastante complexa manter a organização e a cooperação do grupo constituído para esse trabalho.

Havia uma expectativa, de nossa parte, de que os participantes assentados do grupo (que representavam $40 \%$ do total) tivessem, em certos momentos, mobilizado mais meios para obtenção de informações - o que não aconteceu em todos os momentos. Os participantes não residentes no assentamento, por outro lado, queriam conhecer a comunidade e percebemos, em algumas ocasiões, maior esforço na produção de dados por parte deles. Também não conseguimos atribuir o envolvimento dos participantes ao tipo de contrato de trabalho que eles possuíam: diversos participantes tinham contratos temporários (quase metade do total estava nessa categoria) e, ainda assim, tais participantes esforçaram-se para realizar as tarefas propostas e a eles atribuídas.

A partir do que vivenciamos, percebemos que o inventário da realidade, como atividade - para aqueles que fizeram sua construção - e como produto - para aqueles que apenas tiveram acesso às informações socializadas - tem potencial para lidar com problemas próprios das escolas. 


\section{Considerações Finais}

Esta pesquisa teve o objetivo de apresentar o processo de construção coletiva do inventário da realidade 5 por profissionais de duas escolas do campo, localizadas em assentamentos de reforma agrária do município de Londrina, Paraná, bem como de problematizar essa construção e de discutir sobre os resultados obtidos.

A pesquisa-ação ofereceu subsídios para a construção e a análise da pesquisa desenvolvida, de acordo com uma necessidade de interesse da comunidade, para a solução de um problema coletivo, tendo como ponto central o agir participativo do grupo constituído. Ela ofereceu condições para que, após diagnosticada a situação (falta de um material com as informações da comunidade do entorno das escolas do Assentamento Eli Vive), iniciássemos uma ação (a produção dos dados) que proporcionou mudança na realidade social do grupo (a construção do inventário da realidade do entorno das duas escolas) e benefícios aos envolvidos no processo (como atividade de construir o inventário da realidade e como produto resultante dessa atividade).

Este relato, a respeito da construção coletiva do inventário da realidade, no contexto da Educação do Campo, e a consequente discussão sobre o processo, a organização e as dificuldades encontradas pretendem contribuir com profissionais de escolas do campo e pesquisadores que tenham interesse no inventário como um instrumento para superação do desconhecimento da realidade local.

Indicamos, porém, que esse material, produzido a partir de um trabalho coletivo, com suas limitações e potencialidades, é uma primeira versão e necessitará ser revisto constantemente, pois, como o próprio nome diz, deve condizer com a realidade - o que pressupõe uma organização da comunidade para planejar como fazer essa atualização.

\section{Contribuição das Autoras}

Problematização e conceituação: Sachs L e Alves WLL; Metodologia: Sachs L e Alves WLL; Análise: Sachs L e Alves WLL; Redação: Sachs L e Alves WLL.

\section{Notas}

1. Há três escolas no Assentamento Eli Vive, sendo duas, uma municipal e uma estadual, no Assentamento Eli Vive I, e uma, municipal, no Assentamento Eli Vive II. As escolas que participaram dos cursos de 2017 e 2018 foram as duas municipais.

2. Para a produção de dados, foram realizadas, com autorização dos participantes, gravações de áudio dos encontros, posteriormente transcritas. Os trechos transcritos estão grafados em itálico e entre aspas, com a indicação do participante e da data do encontro.

3. Grupos formados por cerca de cinquenta famílias.

4. Estudantes da escola estadual presente no Assentamento Eli Vive I.

5. Aqui, não apresentaremos detalhes a respeito do inventário da realidade propriamente dito, mas o leitor interessado poderá visitá-lo, caso tenha interesse: Alves e Sachs (2020). 


\section{Referências}

ALVES, W. L. L.; SACHS, L. Inventário da realidade: Escola Municipal do Campo Trabalho e Saber; Escola Municipal do Campo Egídio Domingos Brunetto. Londrina, 2020. Disponível em: http://repositorio.utfpr. edu.br/jspui/handle/1/5052. Acesso em: 28 ago. 2020.

CALDART, R. S. Educação do Campo: notas para uma análise de percurso. Trabalho, Educação e Saúde, Rio de Janeiro, v. 7, n. 1, p. 35-64, mar./jun. 2009. https://doi.org/10.1590/S1981-77462009000100003

CALDART, R. S. et al. Inventário da Realidade: guia metodológico para uso nas escolas do campo. Veranópolis: Instituto de Educação Josué de Castro, 2016. Disponível em: https://drive.google.com/file/ d/0B19zVxnRAF8XdENLSXZzOWtzVFE/view. Acesso em: 01 set. 2019.

D’AMBROSIO, U. O Programa Etnomatemática: uma síntese. Acta Scientiae, Canoas, v. 10, n. 1, p. 7-16, jan./jun. 2008. HAMMEL, A. C.; FARIAS, M. I.; SAPELLI, M. L. S. Complexos de Estudo - do inventário ao Plano de Estudos. In: SAPELLI, M. L. S.; FREITAS, L. C.; CALDART, R. (org.). Caminhos para transformação da escola: organização do trabalho pedagógico nas escolas do campo. Ensaios sobre complexos de estudo. São Paulo: Expressão Popular, 2015. p. 67-96.

KOLLING, E. J.; NERY, I. I. J.; MOLINA, M. C. Por uma educação básica do campo (memória). Brasília: Articulação Nacional por uma Educação do Campo, 1999.

MST [MOVIMENTO DOS TRABALHADORES RURAIS SEM TERRA]. Escola Itinerante: Plano de Estudos. Cascavel: Unioeste, 2013.

SACHS. L. Potencialidades do inventário da realidade para escola do campo em áreas de reforma agrária. Hipátia - Revista Brasileira de História, Educação e Matemática, São Paulo, v. 4, n. 1, p. 38-47, jul. 2019.

THIOLLENT, M. Metodologia da pesquisa-ação. 2. ed. São Paulo: Cortez, 1986.

THIOLLENT, M. Pesquisa-ação nas organizações. São Paulo: Atlas, 1997.

\section{Sobre as Autoras}

Línlya SAchs é docente da Universidade Tecnológica Federal do Paraná. Tem bacharelado e licenciatura em Matemática pela Universidade de São Paulo, mestrado em Ensino de Ciências e Educação Matemática pela Universidade Estadual de Londrina e doutorado em Educação Matemática pela Universidade Estadual Paulista Júlio de Mesquita Filho. Seus interesses de pesquisa estão relacionados a Educação Matemática, Educação do Campo, Etnomatemática, Currículo e Formação de Professores.

Whendelly Lorena Leite Alves é professora na rede municipal de educação da prefeitura de Londrina (PR) e tem licenciatura em Matemática e mestrado em Ensino de Matemática pela Universidade Tecnológica Federal do Paraná. Seus interesses de pesquisa estão relacionados à Educação Matemática.

Recebido: 01 maio 2020 